\title{
Situating Kant's Pre-Critical Monadology: Leibnizian Ubeity, Monadic Activity, and Idealist Unity
}

Edward Slowik

\begin{abstract}
This essay examines the relationship between monads and space in Kant's early pre-critical work, with special attention devoted to the question of ubeity, a Scholastic doctrine that Leibniz describes as "ways of being somewhere". By focusing attention on this concept, evidence will be put forward that supports the claim, held by various scholars, that the monad-space relationship in Kant is closer to Leibniz' original conception than the hypotheses typically offered by the later Leibniz-Wolff school. In addition, Kant's monadology, in conjunction with God's role, also helps to shed light on further aspects of his system that are broadly Leibnizian, such as monadic activity and the unity of space.
\end{abstract}

One of the most important developments in Leibniz scholarship over roughly the past quarter century has been the widespread repudiation of the purely idealist or immaterialist interpretation of his late metaphysics (i.e., where only minds/souls and mental content exist, à la Berkeley) for a "realist" reading that accepts the existence of an external world of some sort (see, e.g., Garber 2009). An interestingly upshot of the realist interpretation of Leibniz is the close proximity it places his monadological metaphysics vis-à-vis Kant's own pre-critical period monadology, a point that has been specifically raised by various commentators with respect to the non-spatiality of monads (e.g., Rutherford 2004, 231233). Yet, while Kant's pre-critical monadology does indeed have many features in common with Leibniz' approach, especially concerning the hypothesis that monads are not in space, several key components in Leibniz' and Kant's respective systems have been neglected in prior investigations of their similar monadic schemes: namely, (i) the concept of ubeity, a scholastic distinction that Leibniz discusses in the New Essays as a means of characterizing the different ways that a being can be related to space; (ii) the crucial role that monadic activity or operation assumes in their respective systems; as 
well as (iii), God's function as the grounds or foundation of the monads and the material world. As will be revealed in this essay, a focus on issues (i), (ii), and (iii) sheds new light on the textual evidence, and supports new arguments, concerning the close connection between Leibniz and Kant's respective monadologies, especially as regards the non-spatiality of monads.

In what follows, accordingly, section 1 will examine (i), (ii), and (iii) in Leibniz' monadology, whereas section 2 will be devoted to these same issues as they appear in Kant's pre-critical period output. In the concluding section, a brief defense of the similarities of the separate Leibnizian and Kantian monadic systems will be offered.

\section{Leibniz, Ubeity, and Monadic Activity.}

In his late monadic metaphysics, Leibniz contends that monads are non-extended, partless entities that form bodies, which are also described as composites or aggregates of monads ("bodies are only aggregates", G VII 344; AG 319). ${ }^{1}$ Nevertheless, besides possessing a merely ideal unity (e.g., G II 256), bodies are claimed to "result" from monads, a process that would seem to exclude the straightforward sense of aggregation or composition associated with, say, atomism: "properly speaking, matter is not composed of constitutive unities [monads], but results from them" (G II 268; AG 179). The fact that

\footnotetext{
${ }^{1}$ The following abbreviations will be used for frequently cited works: L = Leibniz 1969; AG = Leibniz 1989; A = Leibniz 1923 (referenced with series, volume, and page number); LC = Leibniz and Clarke 2000 (referenced with Leibniz' letter number and section); LDB = Leibniz 2007; G = Leibniz 1965 (referenced with volume and page number); GM = Leibniz 1962 (referenced with volume and page number); NE = Leibniz 1996 (referenced with book, chapter, section); CSMK = Descartes 1991; N = Newton 2004; TP = Kant 1992, cited with volume, followed by a colon, and page number, from the standard Academy edition of Kant's works (same for other Kant work); NS = Kant 2012.
} 
extended matter results from monads, but is not composed of monads, would seem to be a consequence of his belief that monads are not spatial: "monads in themselves do not even have situation with respect to each other-at least one that is real, which extends beyond the order of phenomena" (May 26, 1712; LDB 241-243). At greater length, he explains that any assignment of spatiality ${ }^{2}$ to monads (nearness, distance, or that they are in points) is misguided:

[T] here is no absolute or spatial nearness or distance between monads. To say that they are crowded together in a point or disseminated in space is to employ certain fictions of our mind when we willingly seek to imagine things that can only be understood. (to Des Bosses, 16 June, 1712; LDB 255; also, G III 623)

However, Leibniz also maintains that monads retain a sort of "derived position" within matter: "although monads are not extended, they nevertheless have a certain ordered relation of coexistence with others, namely, through the machine which they control" (G II 253; L 531). ${ }^{3}$

Leibniz' puzzling claim that his non-spatial monads have A derived position in matter has prompted various interpretations. One possibility is to simply deny that aggregates

\footnotetext{
${ }^{2}$ Henceforth, "spatiality", as used with reference to monads (or God), concerns the relationship between a monad's (God's) being/substance and space; thus, the nonspatiality of monads means that their being or substance is not situated in space, although their actions/operations may be in space (and the same for God). As used with respect to bodies, spatiality refers to their extension in length, breadth, and width; hence, to declare that bodies are non-spatial means that bodies are not really extended (in the external world), but only appear extended.

${ }^{3}$ While the topic of our investigation concerns the question of the spatial situation of Leibniz' monads in his later metaphysics, roughly from the late 1690s onward, it is worth noting that Leibniz' earlier work seems to support the same non-spatial status for souls/minds as one finds in the later output. In a tract from 1668-1670, he writes (in Cartesian vein) that " $[\mathrm{w}]$ hatever is not a body is not in space; for to be in space is the definition of a body" (L 113; G IV 110). The same outlook is likewise in evidence in the middle years, 1680s and 1690s: in A New System of the Nature and the Communication of Substances, from 1695 (G IV 477-487), Leibniz claims that "[m]inds thus have special laws that place them beyond the revolutions of matter" (L 455).
} 
(bodies) are spatial, rather, aggregate spatiality is a further contribution of the mind. Hartz argues that this interpretational strategy does not lead to a Berkeleyan-style idealism since an aggregate "is real, active, and has force" (Hartz 2007, 133). A somewhat similar tactic that also denies the real extension of bodies can be found in Rutherford (1990), who argues that it does not follow from the mind-dependent status of aggregates "that aggregates are nothing real; on the contrary, Leibniz maintains that in terms of their reality aggregates are to be identified with the plurality of things from which they result [monads]" $(1990,20)$. In other words, the fact that monads are constitutive of matter and bodies is inconsistent with idealism: if bodies are merely mental content, then why demand that "an aggregate is nothing other than all those things taken at the same time from which it results" (G II 256)? Consequently, the line of interpretation advanced by Hartz, Rutherford, and others, is to focus on the mind-based aspects of Leibniz' theory, with the emphasis placed on linking the non-spatiality of monads and bodies with the monad's own intentional, mind-dependent states.

But, there is another interpretative approach that, while continuing to emphasize the non-spatiality of monads, need not deny the spatiality of Leibnizian bodies. A discussion in the New Essays on the various ways that a being can be related to place or space provides the basis for this line of interpretation, as will become evident below:

The Scholastics have three sorts of ubeity, or ways of being somewhere. The first is called circumscriptive. It is attributed to bodies in space which are in it point for point, so that measuring them depends on being able to specify points in the located thing corresponding to points in space. The second is the definitive. In this case, one can "define" - i.e. determine - that the located thing lies within a given space without being able to specify exact points or places which it occupies exclusively. That is how some people have thought that the soul is in the body, because they have not thought it possible to specify an exact point such that the soul or something pertaining to it is there and at no other point. Many competent people still take that view.... What should be said about angels is, I believe, about the same as what is said about souls. 
The great Thomas Aquinas believed that an angel can be in a place only through its operations [upon what is there], which on my theory are not immediate and are just a matter of the pre-established harmony. The third kind of ubeity is repletive. God is said to have it, because he fills the entire universe in a more perfect way than minds fill bodies, for he operates immediately on all created things, continually producing them, whereas finite minds cannot immediately influence or operate upon them. (NE II.xxiii.21)

Leibniz rejects the first two ubeity options: circumscriptive ubeity, which maps bodies to space over an extended region in a point by point manner, and definitive ubeity, which only links a spiritual being to a specific place or point within that region. Leibniz opts instead for repletive ubeity, where God "operates immediately" by continually producing things that exist in space. As the context makes clear, much in this discussion concerns finite souls and angels and their relationship to material bodies, a scenario that prompts Leibniz' worries that the definitive account entails that souls can act immediately upon the things in space, with "immediately" pertaining to the soul's acting directly upon things. Leibniz, however, prefers the view where "finite minds cannot immediately influence or operate upon" bodies, and he offers his theory of pre-established harmony as an instance of this better strategy. ${ }^{4}$

In his correspondence with Des Bosses (April 30, 1709), many of these issues resurface in the context of material extension and monads (souls):

Nevertheless, I do not think it appropriate to regard souls as though in points. Perhaps someone might say that souls are not in place but through operation, speaking here according to the old system of influx; or rather, according to the new system of preestablished harmony, that they are in place through correspondence, and

\footnotetext{
${ }^{4}$ It should be noted that Leibniz' interpretation of the ubeity concept is somewhat unique, since the traditional Scholastic conception was as concerned with the finite/infinite extent of the being as well as the manner by which the being is present in space (see, e.g., Grant 1981, 368, n.125). Leibniz, however, centers more upon the way that a being is manifest in space in the NE II.xxiii.21 quotation. Henceforth, our investigation will follow Leibniz' lead and interpret the ubeity distinction as pertaining to the form of spatial presence alone, regardless of whether the being is finite or infinite. See, also, footnote 6 .
} 
that in this way they are in the whole organic body that they animate. On the other hand, I do not deny a certain real metaphysical union between the soul and an organic body ... according to which it can be said that the soul is truly in the body. . . You realize, though, that until now I have been speaking here not of the union of an entelechy or active principle with primary matter or passive power, but the union of the soul or of the monad itself (which results from both principles) with mass, or with other monads. (LDB 123-127)

Leibniz once again puts forward his notion of pre-established harmony as superior to the view that souls are "in place but through operation", which he equates with the "old system of influx". What is important about these passages, NE II.xxiii.21 and LDB 123127 , is that Leibniz does not openly reject the operation of monads, i.e., that a being can be in space only through its operation, a doctrine sometimes known as the "extension of power" ${ }^{\prime 5}$ (hereafter, EP) — rather, as is more clearly stated in the New Essays quotation, what Leibniz rejects is the immediate operation of soul on body, which he associates in the Des Bosses letter with the system of physical influx. As is well-known, a basic tenet of Leibniz' philosophy is the denial that substances causally interact: e.g., "[s]trictly speaking, one can say that no created substance exerts a metaphysical action or influx on

\footnotetext{
${ }^{5}$ In use during the Medieval period, the origin of the term "extension of power" is unclear, but other descriptions include "presence of power", "virtual extension", and "virtual presence". There is an additional issue involved with EP that concerns whether the essence that operates immediately must be "really" present where it acts, as Aquinas and many others had held, or whether the essence need not be really present, as Scotus had argued (see, Grant 1981, 146-147, for a brief survey). In the 1692 correspondence with Pellisson, Leibniz defends the former thesis, stating that "everything that operates immediately in several places also is in several places by a true presence of its essence, and that the immediate operation cannot be judged to be distant from the individual that operates, since it is a manner of being of it" (A.I.vii.294; Adams 1994; 357). In these letters, Leibniz even defines EP as the essence acting non-immediately, i.e., at a distance: "A presence by power [presence virtuelle], as opposed to a real presence, must be without that immediate application of the essence or primitive force, and happens only by actions at a distance or by intermediate operations" (A.I.vii.249; Adams 1994, 356). Yet, by the Des Bosses correspondence, he seems to have reversed himself, such that immediate operations could be at a distance: "if God should bring it about that something immediately operates at a distance, by that fact he would bring about its multipresence" (May 2, 1710; LDB 171).
} 
any other thing" (Primary Truths, AG 33).

To recap, it is for reasons relating to his denial of inter-substance or inter-monadic causation that Leibniz sides with pre-established harmony. Yet, apart from the intermonadic causation issue, Leibniz' reference to the "the old system of influx" would seem to draw a close analogy between, on the one hand, the monad-matter relationship, and, on the other, the immaterial being-matter relationship in those older instances of EP. Leibniz seems willing to concede the general point that a finite entity, soul, angel, or monad, can be conceived as in place through its operations, but only in so far as those operations are not immediate, i.e., there is no influx or real causal interaction, since the influx has been supplanted by the mediation of God's providence in establishing the harmony between the soul and its operations. In contrast, since God "operates immediately on all created things" by "continually producing them" (NE II.xxiii.21), EP does apply to God. There are several other instances in Leibniz' late writings where God's immediate operation is addressed:

God is not present to things by situation but by essence; his presence is manifested by his immediate operation. The presence of the soul is of quite another nature. To say that it is diffused all over the body is to make it extended and divisible. To say it is, the whole of it, in every part of the body is to make it divisible of itself. To fix it to a point, to diffuse it all over many points, are only abusive expressions, idola tribus. (LC.III.12)

Where space is in question, we must attribute immensity to God, and this also gives parts and order to his immediate operations. He is the source of possibilities and of existents alike, the one by his essence and the other by his will. (NE II.xv.2)

To summarize, God is "not present to things by situation but by essence", yet "his presence is manifested by his immediate operations", i.e., his immediate operations are given "parts and order" in space even though God is not situated in space (and where God's "immensity", as used by Leibniz, would seem to pertain to the ontological 
dependence of matter and space on God; see, LC.V.106). Consequently, on Leibniz' interpretation of these issues, to claim that God is present to things by essence is to claim that God's immediate operations are situated in space but not God's being, and where God's essence serves the more general metaphysical role of grounding the possibility of any existing thing. This reading seems to be upheld later in the correspondence with Clarke, for Leibniz rejects the hypothesis that "God discerns what passes in the world by being present to the things", rather, God discerns things "by the dependence on him of the continuation of their existence, which may be said to involve a continual production of them" (LC.V.85). Therefore, because God's immediate operation correlates with the world's continual production, the spatial order of the world situates that act in space. Returning to the Leibniz-Clarke passage above (LC.III.12), Leibniz then proceeds to deny that either a soul is diffused "all over a body", which undoubtedly equates with circumscriptive ubeity in NE II.xxiii.21, or that a soul is, "the whole of it, in every part of the body", which is consistent with his account of definitive ubeity in the same New Essays passage (i.e., the "whole in every part" doctrine would include definitive ubeity as used by Leibniz). ${ }^{6}$

\footnotetext{
${ }^{6}$ Another idiosyncratic aspect of Leibniz' interpretation of these doctrines concerns the scope of EP. As developed by the Scholastics, EP could be linked to a non-extended (or non-dimensional) being, and thus both definitive and repletive ubeity, as defined by Leibniz in NE II.xxiii.21, would meet the definition (since definitive ubeity situates a being in the non-extended points of space). Leibniz, on the other hand, equates EP with his interpretation of repletive ubeity alone, since the LC.III. 12 quotation specifically rules out definitive ubeity ("God is not present to things by situation"). For these reasons, and given their general similarity, EP will be taken as synonymous with repletive ubeity throughout the remainder of the essay, i.e., that the being/substance of God/monads is not in space but the actions of God/monads are in space. Likewise, our usage of the repletive ubeity concept need not include the recreation of the world. Finally, a referee of an earlier draft of this paper has suggested an alternative interpretation of Leibnizian repletive ubeity as regards God: God may not act in space per se, but rather simply act on the non-
} 
For understanding the perplexing issue of the non-spatiality of monads, as well as upholding an interpretation of Leibnizian bodies that accepts their real extension and spatiality, the ramifications of EP are quite significant. Since Leibniz uses the terms "soul" and "monad" interchangeably in his late period, if "souls are not in place but through operation, speaking here according to the old system of influx" (LDB 125), i.e., the immediate operation of monads is hypothetically sanctioned, then monads are, like God, in place/space by way of their operation, but not themselves situated in space. Hence, while Leibniz does not strictly sanction EP for monads, his comments would seem to admit that the relationship between his non-spatial, non-situated monads and extended bodies is similar the relationship between non-spatial, non-situated immaterial beings and extended bodies in the older influx EP theory (but, of course, excluding the influx component of the older theory). This interpretation, which would support the nonsituated component of immaterial beings in the original influx formulation of the EP hypothesis, also explains why monads only have a derived position in space, i.e., through the body which they control. In more detail, since Leibniz states in LDB 127 that "the union of the soul or of the monad itself ... with mass, or with other monads" is the context under which he concedes that monads are in place through their operation (under the influx construal), and since mass is associated with extended secondary matter or aggregates (e.g., G II 252; AG 177), the monads are only in place by means of mass/secondary matter. This inference correlates perfectly with his claims concerning the derived situation of monads: "although monads are not extended, they nevertheless have a certain ordered relation of coexistence with others, namely, through the machine which

spatial monads instead (and hence his claim that God's operations are in space is not meant to be taken literally). 
they control" (G II 253; L 531).

Furthermore, textual evidence supports the contention that monadic activity is spatial, even though the monads are not spatial. In the sentence that directly precedes his comments on the derived situation of monads in matter, L 531, he claims that "every change, spiritual as well as material, has its own place, so to speak, in the order of time, as well as its own location in the order of coexistents, or in space" (G II 253; L 531). And, in a later work, he concludes that "[t]here are simple substances everywhere, actually separated from one another by their own actions" (Principles of Nature and Grace, 1714; G VI 598; AG 207). In both of these instances, the non-spatiality of monads or simple substances is also endorsed, hence the insistence that monadic "change" or "activity" is in space seems to be significant. Yet, what would constitute monadic activity? As we have seen, God's continual production of the world situates that act in space, even though God is not in space- - so, for the advocates of a realistic account of Leibnizian extended bodies, it would seem that this analogy should serve as the foundation of an EP-centered account of the monadic-matter relationship: monads are not in space but their operations are situated in space via extended matter. But, since Leibniz accepts the pre-established harmony view, such that everything that happens is internal to a monad, it might appear that there is little similarity between God's immediate operation, which creates matter, and monadic operation, which only involves the internal properties of monads.

Nevertheless, besides aggregation (which is not an internal property of monads), there is one aspect of the story of how extended bodies result from monads that would appear comparable to an internal monadic operation or activity — namely, the role of force, both 
primitive and derivative. In a discussion of the Eucharist in 1692, Leibniz reasons that "it is not only in the Eucharist, but everywhere else, that bodies are present only by this application of the primitive force to the place" (A.I.vii.249; Adams 1994, 355). And, in his correspondence with De Volder, more details are provided on how the primitive/derivative force distinction is tied to the emergence of bodily extension:

[T] he nature which is supposed to be diffused, repeated, continued [i.e., to form extension of bodies via aggregation], is that which constitutes the physical body; it cannot be found in anything but the principle of acting and being acted upon, since the phenomena provide us with nothing else.... But when force is taken for the principle of action and passion, and is therefore something modified through derivative forces, that is, something modified through that which is momentary in action, you can understand well enough from what has been said that this principle is bound up with the very notion of extension, .... (June 30, 1704; G II 268-270; AG 179-180)

Primitive force, as the principle of action and passion, is "modified through derivative force" in such a way that derivative force is "that which is momentary in action", i.e., derivative force is an instantiation of the monad's primitive force, the latter constituting its essence. For understanding how monadic operation or activity might relate to the rise of extended matter, the references to primitive force as the principle of action, and derivative force as what is momentary in action, is important, for it brings together monadic action or operation and primitive/derivative force, the latter implicated in the account of extended matter ("this principle [primitive/derivative force] is bound up with the very notion of extension"). Although monads are not spatial, derivative force is coupled to the phenomena of extended bodies, which are aggregates of monads, or secondary matter: "the derivative force of being acted upon later shows itself to different degrees in secondary matter" (GM VI 236; AG 120). As a result, monads are not situated in space, but their effects or "results" are spatial via the extended bodies that come about 
from derivative force. It should be noted, however, that this portion of our investigation is fairly speculative, largely due to the difficult nature of the relationship between primitive and derivative force, an aspect of Leibniz' system that seems to have been constantly evolving and remained somewhat tentative.

To recap, there are number of important clues that link Leibniz' monadology to the Scholastic ubeity concept, in particular, definitive ubeity (or EP), and this approach to Leibniz' monadology is consistent with the existence of spatially situated, extended material bodies, just as it was for the Scholastics. In the next section, similar parallels will be disclosed in Kant's pre-critical monadology. ${ }^{7}$

\section{Kant's Pre-Critical Monadology.}

Leibniz' monadic project became an essential element of the natural philosophy of space of the eighteenth century Leibniz-Wolff school, although many of the members of this tradition apparently situated their monads, or soul-like simple substances, in the points of space, unlike Leibniz (see, De Risi 2007, 309 n.8; and Watkins 2005, 58). That

\footnotetext{
${ }^{7}$ It is also worthwhile comparing Leibniz and Descartes on EP, for Descartes had sanctioned that doctrine with respect to God, angels, and minds (souls). In his late correspondence with More, Descartes asserts that "[f]or my part, in God and angels and in our mind I understand there to be no extension of substance, but only extension of power. An angel can exercise power now on a greater and now on a lesser part of corporeal substance; but if there were no bodies, I could not conceive of any space with which an angel or God would be co-extensive" (CSMK 372-373). There is a certain similarity here in that the power of Descartes' spiritual beings and the primitive force of Leibniz' monads still remain even if there are, respectively, no actual Cartesian bodies or no limitation imposed on the primitive force, i.e., derivative force as a particular value of primitive force. On the other hand, while Cartesian matter can exist apart from a spiritual beings' EP, Leibniz' force-based conception of matter, especially secondary matter, denies this possibility. Leibniz was familiar with the Descartes-More correspondence (L 342; G II 117); nevertheless, given Leibniz' knowledge of Scholastic metaphysics, he was almost certainly well acquainted with the EP doctrine and its alternatives apart from the Descartes-More correspondence.
} 
is, many of the followers of Wolff would seem to have opted for definitive ubeity (where the soul/monad is situated in the points of space) over Leibniz' rejection of monadic spatiality. On the other hand, the Wolffians followed Leibniz by associating their simple substances with force, and by conceiving the material world as an emergent or supervenient effect of monadic force. Likewise, many in the Leibniz-Wolff camp sided with Leibniz' conception of space over the absolutism of the Newtonians; e.g., Wolff declares that "space is the order of things that co-exist. And therefore space cannot exist if things are not present to occupy it, although it is still different from these things" (Wolff 2009, 15).

In a series of works, starting with his very first, Thoughts on the True Estimation of Living Forces (1749), and including the Physical Monadology (1756), the pre-critical Kant puts forward his own brand of monadic hypothesis that upholds the relationist—or, more accurately, nominalist — conception of space favored by Leibniz and the Wolffians, but which sides with Leibniz over many of the Wolffians by adamantly rejecting the spatiality of monads. On Kant's reckoning in the True Estimation, the force that comprises his simple substances/monads can interact with one another, and by these interactions they give rise to space: "there would be no space and no extension if substances had no force to act external to themselves. For without this force there is no connection, without connection, no order, and, finally, without order, no space" (NS 1:23). Furthermore, since Kant's substances, which are associated with souls in the standard Leibniz-Wolff fashion (1:21), are not in space per se, it follows that a substance that does not partake in their mutual interconnections would not be in space.

A substance is either connected with and related to other substances external to it, or it is not. Because every independent entity contains within itself the complete source 
of all its determinations, it is not necessary for its existence that it should stand in any connection with other things. That is why substances can exist and nonetheless have no external relation to other substances, or have no real connection with them. Now since there can be no location without external connections, positions, and relations, it is quite possible that a thing actually exists, yet is not present anywhere in the entire world (1:22-23).

Given this hypothesis, Kant further contends that "God may have created many millions of worlds" (1:22), presumably, by interconnecting different sets of substances to form different worlds along with their different spaces. The type of force-based interconnection among the substances is, furthermore, "the inverse-square relation of the distances" (1:24), an interconnection that also accounts for the three-dimensionality of space, although it is only one of the possible connections (and hence dimensions of space) that God could have established (1:23-25). In his later New Elucidation (1755), Kant adds that the inverse-square law of "Newtonian attraction" that holds among bodies is derived from the inverse-square connection among simple substances: "[i]t is ... probable that this attraction [Newtonian attraction] is brought about by the same connection of substances, by virtue of which they determine space" (TP 1:415). ${ }^{8}$

\footnotetext{
${ }^{8}$ There is an interesting problem (which was raised by a reviewer) concerning force on Kant's model: if force is prior to space, then how do we understand the distance relationships, such the $1 / \mathrm{r}^{2}$, that are incorporated into his conception of monadic force (as in NS 1:23 and TP 1:415 above). Kant does not address this issue, but his assertion that space "is the appearance of the external relations of unitary monads" (TP 1:479) suggests a possible response: any force manifest at the macrolevel of bodies that involves spatial distance, such as $1 / \mathrm{r}^{2}$, is an "appearance" (phenomena); i.e., the interconnections among monads are not spatiotemporal relations, but they nonetheless "bring about" matter, space, and the distance-based conception of force, at the material (phenomenal) level. Furthermore, it should be noted that Kant, as a dedicated Leibniz-Wolffian, was well informed on Leibniz' views: even though the New Essays would not appear until after the pre-critical monadological works, the Leibniz-Clarke correspondence was available during that time, and many of Leibniz' claims about the non-spatiality of God, etc., are discussed at length in the correspondence. And, as Rutherford (2004, 231-233) has correctly noted, Kant's interpretation of Leibniz was much more accurate than his fellow
} 
One of the uncertainties related to Kant's early monadic philosophy in the True Estimation, however, pertains to the possible spatial presence of these substances after space emerges from their interconnections. As is evident in the long quotation provided above, "since there can be no location without external connections", it would seem to be the case that substances are located once these external connections are established. In the Physical Monadology, Kant sets out to address this issue, since it potentially leads to a problem that Newton had earlier confronted in De grav (N 24-26) i.e., if space is divisible and the foundational entities from which space emerges are situated in space, then these allegedly indivisible entities must be, on the contrary, divisible. Kant's solution, which parallels Leibniz' primitive/derivative force distinction (see chapter 4), invokes a difference between a monad's non-spatial "internal determinations" and its "external determinations", or "sphere of activity", the latter giving rise to space. "[T]hough any monad, when posited on its own, fills a space", explains Kant, yet "the filled space is not to be sought in the mere positing of a substance but in its relation with respect to substances external to it. ... It must, therefore, be granted that the monad fills the space by the sphere of its activity" (TP 1:481). Described as an "accident" of the monad, he further identifies the sphere of activity with impenetrability (1:482).

It is at this point that our lengthy discussion of Leibniz' version of ubeity, introduced in section 1, enters the picture. Returning to the divisibility worry, Kant provides a detailed account of his version of monadic presence:

But, you say, substance is to be found in this little space and is everywhere present within it; so, if one divides space, does not one divide substance? I answer: this space itself is the orbit of the external presence of its element. Accordingly, if one divides

Leibniz-Wolff philosophers. However, Leibniz and Kant's respective monadologies differ in various other ways, some which will be discussed in section 3 . 
space, one divides the extensive quantity of its presence. But, in addition to external presence, that is to say, in addition to the relational determination of substance, there are other, internal determinations; if the latter did not exist, the former would have no subject in which to inhere. But the internal determinations are not in space, precisely because they are internal. Accordingly, they are not themselves divided by the division of the external determinations. ... It is as if one were to say that God was internally present to all created things by the act of preservation; and that thus someone who divides the mass of created things divides God, since that person divides the orbit of His presence - and than this there is nothing more absurd which could be said. (1:481)

By adopting this strategy, Kant has, in fact, adopted Leibniz' preferred form of ubeity for his own monadological hypothesis - and, quite importantly, he supports his conclusion by offering an analogy between a monad's sphere of activity and God's presence "to all created things by the act of preservation", a description that exactly matches Leibniz' account of repletive ubeity, whereby God “operates immediately on all created things, continually producing them" (NE II.xxiii.21; see section 1). That is, just as Leibniz characterizes God's repletive ubeity through the act of preserving the world, an hypothesis that rejects the presence in space of God's substance per se, so Kant posits a corresponding form of monadic repletive ubeity (or extension of power) doctrine that similarly denies the presence in space of a monad's internal determinations, where internal determinations are associated with the monad's substance or being per se, and the external determinations that give rise to space are accidents of the monad's substance (internal determinations). This interpretation of the internal/external determination distinction is corroborated in his discussion of the division problem: although one can divide a monad's sphere of activity into two parts, he concludes that "each [half of the monad's sphere of activity] is nothing but an external determination of one and the same substance, but accidents do not exist independently of their substances" (TP 1:482). As argued in section 1, Leibniz also makes an analogy between a monad's operation/activity 
in space and the extension of power doctrine, the latter including God's continual preservation of the world (via repletive ubeity), but hesitates since he apparently associates the extension of power hypothesis for lesser beings with a physical influx, which he rejects (preferring his pre-established harmony thesis instead). Kant, as we have seen, openly supports a type of physical influx among monads via their external determinations, although he argues in the New Elucidation that these monadic interconnections do not constitute a physical influence "in the true sense of the term" because they are "outside the principle of substance, considered as existing in isolation" (1:415-416). In the language of the Physical Monadology, this would amount to the claim that the external determinations among monads do not involve or modify their internal determinations, even though the external determinations are accidents of internal determinations. And, since Kant claims that his form of inter-monadic connection incorporates a "reciprocal dependency", a dependency that he deems to be more robust than the mere "agreement among substances" that one finds in Leibniz' pre-established harmony doctrine (1:415), it hence follows that the Physical Monadology represents one the most elaborate attempts to defend the non-spatially situated component of Leibniz' original monadological hypothesis alongside a full-fledged notion of inter-monadic activity or interconnection.

Finally, the New Elucidation offers an hypothesis that implicates God's preservation of the world as the foundation of the intermonadic connections, once again demonstrating that repletive ubeity underlies Kant's monadic philosophy:

[T] he ground of their [monadic] reciprocal dependence upon each other must also be present in the manner of their common dependence on God. How that is brought about is easy for the understanding to comprehend. The schema of the divine understanding, the origin of existences, is an enduring act (it is called preservation); 
and in that act, if any substances are conceived by God as existing in isolation and without any relational determinations, no connections between them and no reciprocal relation would come into being. (TP 1:413-414)

In a similar vein, Leibniz had earlier claimed that "a monad, like a soul, is, as it were, a certain world of its own, having no connections of dependency except with God" (5 February 1712, AG 199). Kant, of course, differs from Leibniz in that he sanctions intermonadic connections in addition to God's function as the ontological grounds of the entire monadic system. Yet, this explanation, which appeals to God's "understanding" and "conceiving" to bring space into being (via the intermonadic connections), can also be seen as anticipating the final destination of Kant's evolving conception of space: while divine cognition may no longer play this fundamental role in his later work, a subjectivist/idealist construction of space would remain, albeit limited to the human sphere.

To be more specific, there is an interesting connection between, on the one hand, Kant's appeal in his early pre-critical writings to God's "understanding" as the bind that ties the monadic (and thus spatial) world together, and, on the other, the role of human cognition as the grounds of the unity of space in the critical period. In the Directions in Space (1768), where Kant first launches his criticisms of spatial relationism (via the incongruent counterparts argument) and invokes absolute space, there is no corresponding endorsement of the ontology of absolute space. Rather, Kant seems already inclined towards an idealist interpretation of absolute space, for he concludes that "absolute space is not an object of outer sensation; it is rather a fundamental concept which first of all makes possible all such outer sensation" (TP 2:383). The transformation to space as an a priori intuition, which is tentatively suggested in Directions in Space, is 
forthrightly defended just two years later in the Inaugural Dissertation (1770): "Space is not something objective and real, nor is it a substance, nor an accident, nor a relation: it is, rather, subjective and ideal; it issues from the nature of the mind in accordance with a stable law as a scheme, so to speak, for co-ordinating everything which is sensed externally" (TP 2:403). In short, there is evidence that, from at least the mid-1750s, Kant was disposed to the idea that that the unity of space requires an intellectual or cognitive grounding, a position that evolved from the God-based monadological system of New Directions to the form of the intuition of space in the Critique.

\section{Conclusion.}

By way of conclusion, it would be useful to defend the conclusions reached in this essay against a likely set of criticisms. Leibniz and Kant's respective monadic systems, it will be argued, are drastically different in their philosophical orientation, the former presenting an idealist system while the latter puts forward a realist system. This type of critique has been advanced by Michael Friedman, who contends that, for Kant, space "is derivative from or constituted by the underlying non-spatial reality of simple substances", and is "metaphysically real", whereas Leibniz' "space is ideal because relations between substances are ideal" (Friedman 1992, 7-8). While there are indeed significant differences in their respective monadological systems, our investigation rejects a purely phenomenalist (or anti-realist) reading of Leibniz, since his metaphysics includes numerous realist descriptions of the manner by which material extension (and thus space, when generalized) is brought about by the monads, an issue that has been discussed in considerable detail in section 1. Besides the primitive/derivative force distinction, there 
are many other references to the "diffusion of materiality or antitypy" (e.g., AG 261) in

Leibniz' corpus. Although there are no direct intermonadic connections, Leibniz'

plenum, primitive/derivative force dichotomy, and the diffusion of resistance provide the same "metaphysically real" depiction of the material world that Friedman finds in Kant's pre-critical monadology. ${ }^{9}$ Likewise, Friedman contends that the appeal to God's role in fixing the intermonadic connections (see section 2) heralds the transition from the Leibniz-Wolff doctrine of space to "the Newtonian doctrine of divine omnipresence" $(1992,7)$. While Kant does employ this terminology, such as by referencing the "infinite extent of divine presence" (NS 1:306), there are, as revealed in section 1, many different ways that God can be related to space (ubeity) — and, as disclosed in section 2, Kant follows Leibniz in sanctioning repletive ubeity, whereas Newton's many comments would seem to favor the circumscriptive variety (or, less plausibly, definitive ubeity): e.g., "So the quantity of the existence of God is . . . infinite in relation to the space in which he is present; and the quantity of the existence of a created thing . . . in relation to

${ }^{9}$ A modified version of the above argument might contend that Kant's monads in his Physical Monadology are (as the title of the work states) physical, and not mind-like or immaterial, and thus there is a significant difference between the two monadological systems (since Leibniz' monads are mind-like). Yet, since Kant clearly thinks that his monads have mind-like aspects in the 1747 True Estimation (see, e.g., NS 1:21), evidence would need to be provided that he had changed his view. But, not only is there is no evidence to support this claim, the texts actually support the opposite position: in the New Elucidation of 1755-just one year prior to the Physical Monadology-Kant provides a very Leibnizian conception of substance that includes both aspects, body and mind, even though he refutes various Leibnizian conceptions, such as the pre-established harmony thesis (e.g., TP 1:411-412); and, as late as The Only Possible Argument (1763), he argues that the will and understanding can only belong to a simple substance (God), and that God is the grounding of will and understanding in all other substances (e.g., TP 2:87-88). All of these assertions support the view that Kant's monads/simple substances have both mind/soul and material aspects. Moreover, the Physical Monadology is a short work that, roughly, is only intended to address the physical problem of whether or not cutting space also cuts a monad's substance (i.e., the mind is not relevant to this problem, which is why it is not discussed). 
the size of its presence, it is as great as the space in which it is present" (N 25-26). All told, there are several close parallels between Leibniz and Kant's respective monadic systems, but, regarding Newton and Kant's spatial ontology, not so much.

Finally, one might protest that the strategy that Kant employs in the Physical Monadology, i.e., that dividing the space of a monad's (or soul's) activity does not divide the substance of the monad (soul), had many adherents other than Leibniz, especially among the Scholastics. Consequently, Kant's reasoning that mimics the repletive ubeity concept (extension of power doctrine) may only be accidentally similar to Leibniz' analogous approach. While this objection certainly has merit, since Kant was well informed on the history of philosophical ideas apart from just Leibniz' corpus, Kant was also quite familiar with the Leibniz-Clarke correspondence, a work that lays out Leibniz' non-spatial approach to God and souls (see section 1) along with all of the ontological worries associated with dividing a space in which God/soul is present. Consequently, it seems implausible to suppose that Kant's strategy was not influenced, at least to some degree, by Leibniz' similar conception. Yet, regardless of the source of the inspiration for Kant's maneuver in the Physical Monadology, there are strong parallels between their respective monadological systems, and these similarities reveal the continuing influence of a "present by action, but not present by substance" metaphysics. As noted at the outset, this component of Kant's pre-critical system has received scant attention by commentators, but it is crucial to a full understanding of the pre-critical period.

\section{REFERENCES}

Adams, R. (1994). Leibniz: Determinist, Theist, Idealist. Oxford: Oxford University Press. 
De Risi, V. (2007). Geometry and Monadology: Leibniz's Analysis Situs and Philosophy of Space. Basel: Birkhäuser.

Descartes, R. (1991). The Philosophical Writings of Descartes, Vol.3, The Correspondence, eds. and trans. by J. Cottingham, et al. Cambridge: Cambridge University Press.

Friedman, M. (1992). Kant and the Exact Sciences. Cambridge: Harvard University Press.

Garber, D. (2009). Leibniz: Body, Substance, Monad. Oxford: Oxford University Press.

Grant, E. (1981). Much Ado About Nothing: Theories of Space and Vacuum from the Middle Ages to the Scientific Revolution. Cambridge: Cambridge University Press.

Hartz, G. A. (2007). Leibniz’s Final System. London: Routledge.

Kant, I. (1992). Theoretical Philosophy: 1755-1770, trans. and ed. by D. Walford and M. Meerbote. Cambridge: Cambridge University Press.

Kant, I. (2012). Natural Science, ed. by E. Watkins, trans. by L. W. Beck, J. B. Edwards, O. Reinhardt, M. Schönfeld, and E. Watkins. Cambridge: Cambridge University Press.

Leibniz, G. W. (1923). Sämtliche Schriften und Briefe, ed. by Akademie der Wissenschaften der DDR. Darmstadt and Berlin: Akademie-Verlag.

Leibniz, G. W. (1962). Leibnizens Mathematische Schriften, ed. by C. I. Gerhardt. Hildesheim: Olms.

Leibniz, G. W. (1965). Die Philosophischen Schriften von Leibniz, ed. by C. I. Gerhardt. C. I. Hildesheim: Olms.

Leibniz, G. W. (1969). Leibniz: Philosophical Letters and Papers, 2nd ed., ed. and trans. by L. E. Loemker. Dordrecht: Kluwer.

Leibniz, G. W. (1989). Leibniz: Philosophical Essays, ed. and trans. by R. Ariew and D. Garber. Indianapolis: Hackett.

Leibniz, G. W. (1996). New Essay on Human Understanding, ed. and trans. by P. Remnant and J. Bennett. Cambridge: Cambridge University Press.

Leibniz, G. W. (2007). The Leibniz-Des Bosses Correspondence, ed. and trans. by B. Look and D. Rutherford. New Haven: Yale University Press. 
Leibniz, G. W. and S. Clarke (2000). Leibniz and Clarke Correspondence, ed. and trans. by R. Ariew. Indianapolis: Hackett.

Newton, I. (2004). Philosophical Writings, trans. and ed. by A. Janiak and C. Johnson. Cambridge: Cambridge University Press.

Rutherford, D. (1990). "Phenomenalism and the Reality of Body in Leibniz's Later Philosophy", Studia Leibnitiana, 22, 11-28.

Rutherford, D. (2004). "Idealism Declined: Leibniz and Christian Wolff”, in Leibniz and His Correspondents, ed. by P. Lodge. Cambridge: Cambridge University Press, 214-237.

Watkins, E. (2005). Kant and the Metaphysics of Causality. Cambridge: University of Cambridge Press.

Wolff, C. (2009, [1720]). Rational Thoughts on God, the World and the Soul of Human Beings, Also All Things in General, ed. and trans. by E. Watkins in, Kant's Critique of Pure Reason: Background Source Materials. Cambridge: Cambridge University Press, 753. 